\title{
Editorial \\ What we still don't know about AIDS
}

\author{
Miranda Robertson
}

A great deal is known about the human immunodeficiency virus (HIV) that causes acquired immune deficiency syndrome (AIDS) [1], one of whose cardinal features is its exquisite adaptation to its human host. It enters the body through damaged epithelia, or more insidiously, through specialized cells ( $\mathrm{M}$ cells) in the intestinal epithelium whose function is to deliver viruses and bacteria to waiting immune cells in the tissue below. There, the virus binds to a specialized receptor on the surface of one of these cells - the dendritic cells, which play a central part in activating the $\mathrm{CD}_{4}{ }^{+} \mathrm{T}$ lymphocytes whose destruction by the virus ultimately and lethally disables the immune system. Recognition of the bound virus causes the dendritic cell to migrate to the lymphoid tissues where it engages with the $\mathrm{CD}^{+} \mathrm{T}$ lymphocytes that it activates. This enables the virus to bind to molecules on the surface of the T cell - a highly specific interaction involving the $\mathrm{CD} 4$ molecules that give $\mathrm{CD}_{4}{ }^{+} \mathrm{T}$ cells their name and that enables the virus to enter the cell. Once the virus is inside the cell, it produces DNA copies of its genome that integrate into the host DNA where cellular transcriptional regulators specifically induced by activation of $\mathrm{CD}_{4}^{+} \mathrm{T}$ cells are instrumental in activating transcription of the viral genome to produce more viruses.

A great deal is unknown about what happens to the adaptive immune system in consequence of this fiendish and focused assault. The adaptive immune system consists of the lymphocytes that provide lasting immunity, and $\mathrm{CD}^{+}{ }^{+} \mathrm{T}$ lymphocytes are essential to activating most of adaptive immunity. The loss of these cells in HIV infection thus punches an enormous hole in the immune defences of the host. But $\mathrm{CD}_{4}^{+} \mathrm{T}$ cells are homeostatically selfrenewing, and it is still unclear exactly why they are progressively lost in HIV infection. It is also unclear what happens to the dynamics of the immune system. HIV infection, paradoxically, is characterized by generalized immune activation the basis for which is not understood. These lacunae in understanding are due at least partly to limitations to the research tools available to investigate these phenomena.

Because of its intimate and specific dependence on the host cell machinery, HIV infects only humans, although there is a monkey counterpart, SIV, that produces a syndrome similar to AIDS in rhesus macaques. (Rhesus macaques are not the natural host of SIV: in sooty mangabeys, which are, it causes little inconvenience - another phenomenon that is not understood.) So AIDS can be investigated only in humans and monkeys, which are cumbersome and limited experimental tools. Mice, whose immune systems are the best-understood in the animal kingdom and which offer ease of maintenance and manipulation, have no equivalent pathogen.

With this in mind, George Kassiotis and colleagues set out to generate a mouse in which, as in human HIV infection, $\mathrm{CD} 4^{+} \mathrm{T}$ cells are killed on activation. They did this by a feat of genetic engineering involving Cre-lox and the A fragment of diphtheria toxin (DTA) and which is described both in their paper in this issue of Journal of Biology [2] and, more succinctly, in the accompanying commentary [3]. Investigation of the engineered mouse has led them to the conclusion that at least some of the disturbance to immune dynamics in HIV infection may be due to the preferential destruction of a highly topical and much-invoked subset of $\mathrm{CD}_{4}{ }^{+} \mathrm{T}$ cells called regulatory $\mathrm{T}$ cells. In the accompanying commentary, Nienke Vrisekoop, Judith Mandl and Ronald Germain explain what is known and what is not known about immune dynamics in HIV infection, where the mouse results are and are not consistent with what we know, and what the value of this tool may be.

One way or another, the $\mathrm{CD}_{4}{ }^{+} \mathrm{T}$ cell conditional mutant mouse may help to close the gap between the detailed understanding of the molecular and cell biology of HIV infection, and the very imperfect understanding of the impact of HIV on T cell dynamics.

Miranda Robertson, Editor

editorial@jbiol.com

\section{References}

1. DeFranco AL, Locksley RM, Robertson M: Immunity: The immune response in infectious and inflammatory disease. London: New Science Press; 2007, 252-257 and 326-327.

2. Marques R, Williams A, Eksmond $U$, Wullaert A, Killeen N, Pasparakis M, Kioussis D, Kassiotis G: Generalized immune activation as a direct result of activated $\mathrm{CD} 4^{+} \mathrm{T}$ cell killing. $\mathrm{J}$ Biol 2009, 8:93.

3. Vrisekoop N, Mandl JN, Germain RN: Life and death as a T lymphocyte: from immune protection to HIV pathogenesis. J Biol 2009, 8:91.

Published: 27 November 2009

doi:10.1186/jbiol200

(c) 2009 BioMed Central Ltd 